\title{
Examining and validating a bankruptcy prediction models in Malaysia
}

\begin{abstract}
The purpose of this paper is to propose and validate the combined model for bankruptcy prediction for the Malaysian firms. This combined model is adopted from previous studies by combining Ohlson logit model, Springate-Canadian model and macroeconomic factors. The proposed combined model is developed by using the financial and macroeconomic constructs. The result indicates that logistic regression performs well and it is used to validate the model. Our results also show that, the capacity of the proposed model to predict correctly is $100 \%$ for both samples (distress and non-distress firms). Finally, the results of this study could also be applicable to business and investor's decision making contexts other than the bankruptcy prediction model.
\end{abstract}

Keyword: Bankruptcy prediction; Combined model; Logistic regression; Financial distress 